\title{
Comparison of two maxillary protraction protocols: tooth-borne versus bone-anchored protraction facemask treatment
}

\author{
Peter Ngan ${ }^{{ }^{*}}$, Benedict Wilmes ${ }^{2}$, Dieter Drescher ${ }^{2}$, Chris Martin $^{1}$, Bryan Weaver $^{3}$ and Erdogan Gunel ${ }^{4}$
}

\begin{abstract}
Background: Protraction facemask has been advocated for treatment of class III malocclusion with maxillary deficiency. Studies using tooth-borne rapid palatal expansion (RPE) appliance as anchorage have experienced side effects such as forward movement of the maxillary molars, excessive proclination of the maxillary incisors, and an increase in lower face height. A new Hybrid Hyrax bone-anchored RPE appliance claimed to minimize the side effects of maxillary expansion and protraction. A retrospective study was conducted to compare the skeletal and dentoalveolar changes in patients treated with these two protocols.
\end{abstract}

Methods: Twenty class III patients ( 8 males, 12 females, mean age $9.8 \pm 1.6$ years) who were treated consecutively with the tooth-borne maxillary RPE and protraction device were compared with 20 class III patients (8 males, 12 females, mean age $9.6 \pm 1.2$ years) who were treated consecutively with the bone-anchored maxillary RPE and protraction appliances. Lateral cephalograms were taken at the start of treatment and at the end of maxillary protraction. A control group of class III patients with no treatment was included to subtract changes due to growth to obtain the true appliance effect. A custom cephalometric analysis based on measurements described by Bjork and Pancherz, McNamara, Tweed, and Steiner analyses was used to determine skeletal and dental changes. Data were analyzed using a one-way analysis of variance.

Results: Significant differences between the two groups were found in 8 out of 29 cephalometric variables $(p<.05)$. Subjects in the tooth-borne facemask group had more proclination of maxillary incisors (OLp-Is, Is-SNL), increase in overjet correction, and correction in molar relationship. Subjects in the bone-anchored facemask group had less downward movement of the "A" point, less opening of the mandibular plane (SNL-ML and FH-ML), and more vertical eruption of the maxillary incisors.

Conclusions: The Hybrid Hyrax bone-anchored RPE appliance minimized the side effect encounter by tooth-borne RPE appliance for maxillary expansion and protraction and may serve as an alternative treatment appliance for correcting class III patients with a hyperdivergent growth pattern.

\section{Background}

Several studies have recommended early treatment of developing class III malocclusion for growth modification [1-5]. The validity of two-phase treatment is supported by studies that show greater orthopedic response when treatment is started in younger patients [6,7]. Other studies reported early correction of the malocclusion allows for a

\footnotetext{
* Correspondence: pngan@hsc.wvu.edu

'Department of Orthodontics, School of Dentistry, West Virginia University, 1073 Health Science Center North, P.O. Box 9480, Morgantown, WV 26506, USA

Full list of author information is available at the end of the article
}

favorable growth environment for dentofacial development and may help in preventing development into more severe malocclusion in late adolescence [8]. Early class III treatment using protraction facemask in conjunction with rapid palatal expansion (RPE) appliance has been shown to be successful in correcting skeletal class III malocclusions that are due primarily to deficient maxillary development [9-11]. The protraction facemask generates an anteriorly directed force on the maxilla. The forces act indirectly on the circummaxillary sutures, which are still patent at an early age, and thereby stimulate bone apposition in the suture areas. The goal of combining the RPE with 
Table 1 Age distribution for the control, tooth-borne, and bone-anchored protraction facemask groups

\begin{tabular}{|c|c|c|c|c|c|c|c|c|c|}
\hline & \multicolumn{3}{|c|}{ Control } & \multicolumn{3}{|c|}{ Tooth-borne protraction facemask } & \multicolumn{3}{|c|}{ Bone-anchored protraction facemask } \\
\hline & to & $\mathrm{t} 1$ & Diff & $\mathrm{t} 1$ & t2 & Diff & $\mathrm{T} 1$ & $\mathrm{~T} 2$ & Diff \\
\hline Mean & 9.0 & 9.8 & 0.8 & 9.7 & 10.5 & 0.8 & 9.8 & 10.4 & 0.6 \\
\hline SD & 1.8 & 1.6 & 1.6 & 1.6 & 1.6 & 1.6 & 1.2 & 1.2 & 1.2 \\
\hline Min & 6.1 & 6.9 & & 6.90 & 7.11 & & 8.0 & 9.0 & \\
\hline Max & 12.7 & 13.2 & & 13.2 & 14.1 & & 12.0 & 13.0 & \\
\hline
\end{tabular}

protraction facemask is to provide a more effective protraction of the maxilla by disarticulating the circummaxillary sutures $[12,13]$.

Conventional protraction facemask therapy, with an indirect application of force to the sutures through tooth-borne anchorage, causes both skeletal and dental changes because the applied force was directed below the center of resistance of the maxilla, resulting in a counterclockwise rotation of the maxilla, backward rotation of the mandible, labial tipping of the maxillary incisors, and lingual tipping of the mandibular incisors. This is usually accompanied by an increase in lower face height and a decrease in overbite [9-12]. The goal of protraction facemask therapy is to obtain pure skeletal changes with minimal undesirable dental effects. Previous studies have shown that tooth-borne protraction facemask therapy have undesirable side effects such as excessive forward movement and extrusion of the maxillary molars, excessive proclination of the maxillary incisors, and an increase in lower face height [14-17]. This is a concern especially in situations in which preservation of arch length is necessary. Attempt has been made in designing an absolute anchorage system for maxillary protraction. These newer treatment modalities include the use of intentionally ankylosed maxillary deciduous canines [18], osseointegrated titanium implants $[19,20]$, onplants [21], miniscrews, and most recently miniplates [22-33]. Each implant system has strengths and weaknesses. The use of osseointegrated titanium, onplants, and miniplates required invasive surgical procedures. To simplify the placement of bone-anchored devices, Wilmes et al. introduced the Hybrid Hyrax RPE appliance, a toothand bone-anchored device [23, 24, 32, 33]. Two miniimplants are placed in the anterior palate, and an expansion device is connected to the mini-implants and the first molars. After expansion, the patient undergoes facemask therapy with elastics attached to the hooks on the Hybrid Hyrax expansion appliance. Several case reports have been published on the application of this device [23, 24, 32, 33]. To date, no literature has been presented comparing the results of the Hybrid Hyrax bone-anchored protraction facemask with the tooth-borne protraction facemask treatment. The purpose of this study is to compare the skeletal and dentoalveolar changes between the two treatment protocols. The null hypothesis is that there is no difference in treatment effects for the sagittal, vertical, and angular changes between the two maxillary protraction protocols.

\section{Methods}

This study was approved by the Institutional Review Board of West Virginia University (1401168542). Approval was also granted from one of the authors (B.W.) for the use of orthodontic records from his office. The study groups consisted of 20 patients (8 males, 12 females) who were treated consecutively by the toothborne RPE appliance and protraction facemask and 20 patients ( 8 males, 12 females) who were treated consecutively by the bone-anchored Hybrid Hyrax expansion appliance and protraction facemask. Table 1 shows the age distribution of the two experimental groups. The inclusion criteria for patient selection were class III malocclusion at the time of the initial observation (T1) as defined
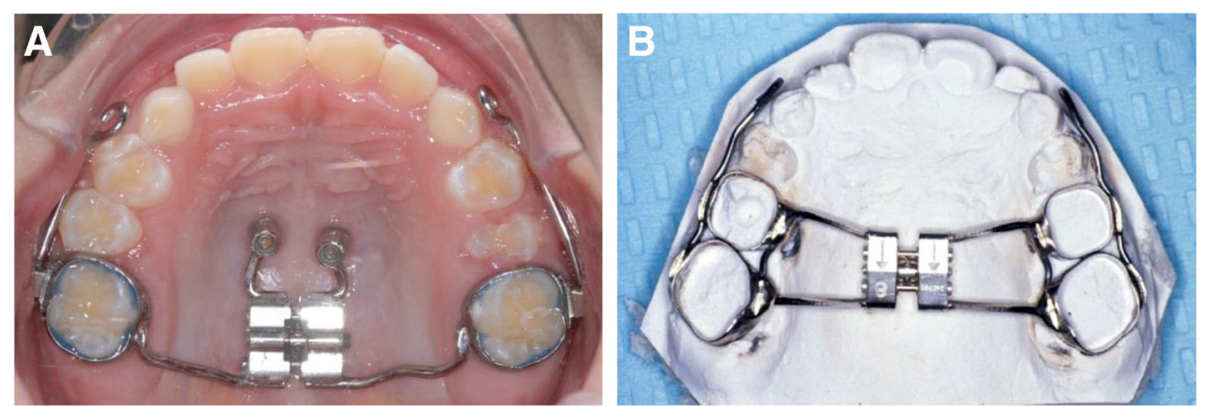

Fig. 1 a Bone-anchored Hybrid Hyrax expansion appliance. b Tooth-borne Hyrax expansion appliance 
by one or more of the following characteristics: anterior crossbite or edge-to-edge incisal relationship; accentuated mesial step or class III permanent molar relationship; a Wits appraisal smaller than $-3 \mathrm{~mm}$ or an ANB smaller than $-2^{\circ}$. The exclusion criteria were no prior orthopedic or orthodontic treatment and no craniofacial syndromes. A sample consisted of 20 class III patients with no treatment who were under observation for class III treatment and matched closely in age and craniofacial morphology with the study groups were used as the control group.

\section{Appliances for class III correction}

The tooth-borne RPE was constructed by placing bands on the posterior teeth (Fig. 1a). Bands were fitted on the maxillary primary second molars and permanent first molars. These bands were joined by a heavy wire $(.043 \mathrm{in}$.) to the palatal plate, which had a jack screw in the midline. The appliance was activated twice daily $(0.25 \mathrm{~mm}$ per turn) by the patient for 1 week. In patients with a constricted maxilla, activation of the expansion screw was applied for 2 weeks. A 0.045 -in. wire was soldered bilaterally to the buccal aspects of the molar bands and extended anteriorly to the canine area with a hook for protraction elastics.

The bone-borne Hybrid Hyrax RPE was constructed by placing bands on the permanent first molars (Fig. 1b). Two Benefit micro-implants $(2 \mathrm{~mm} \times 9 \mathrm{~mm}$, PSM

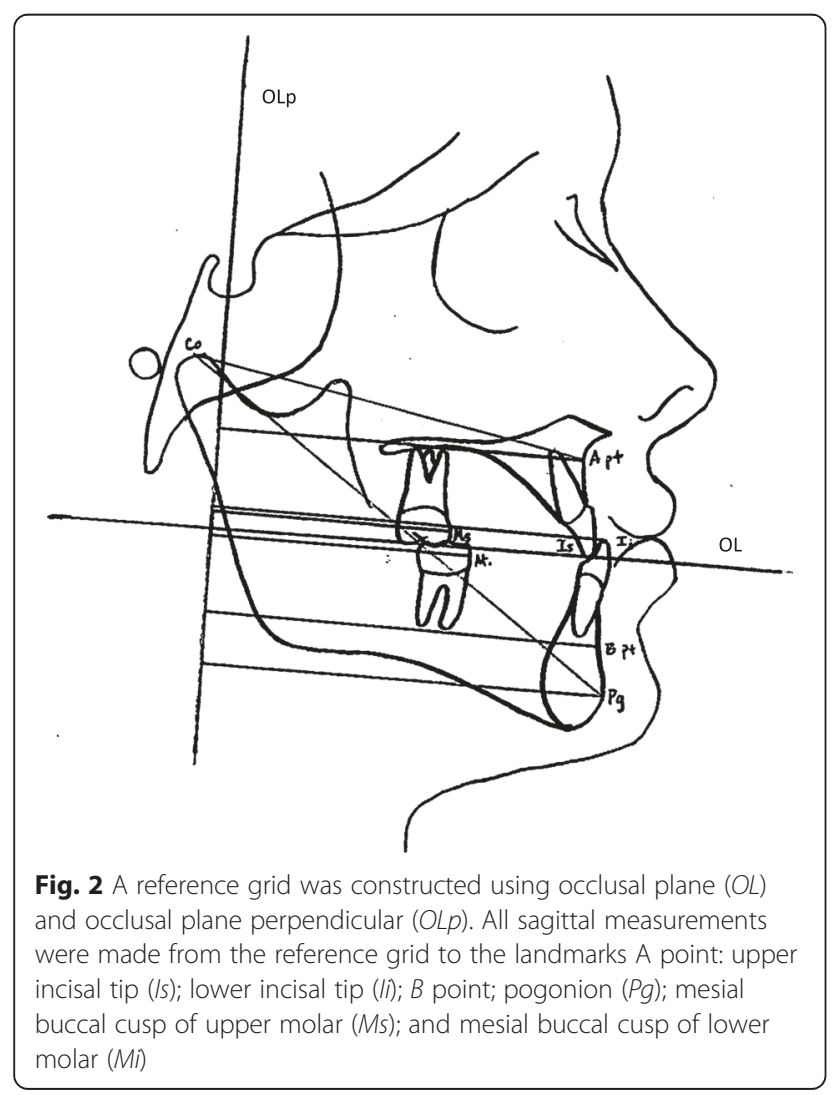

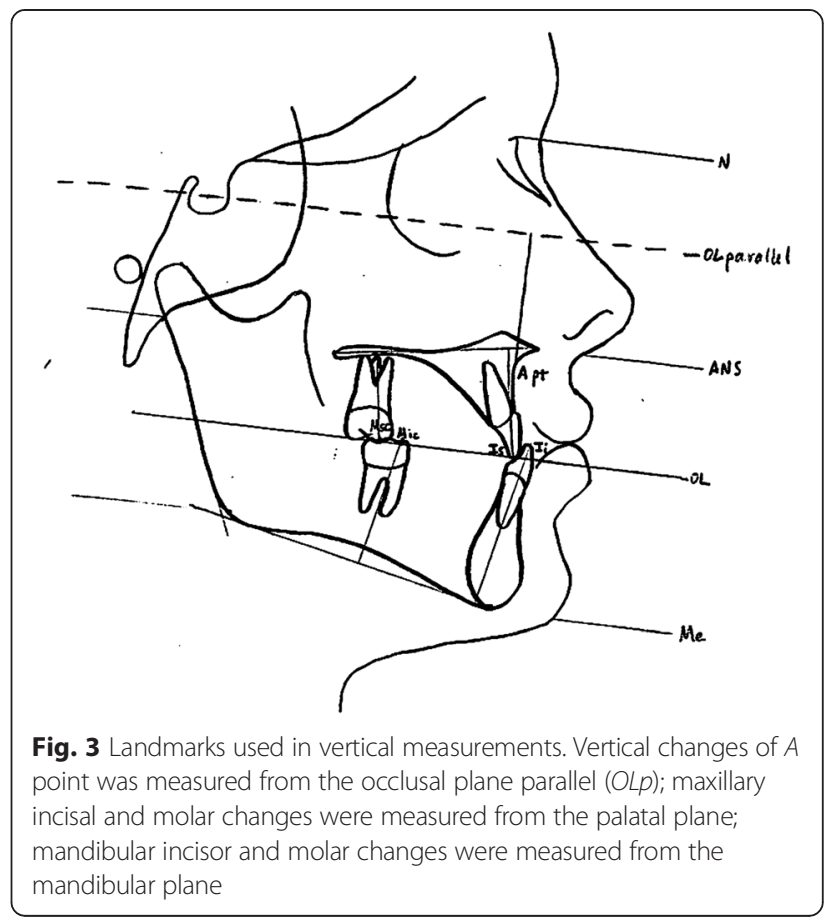

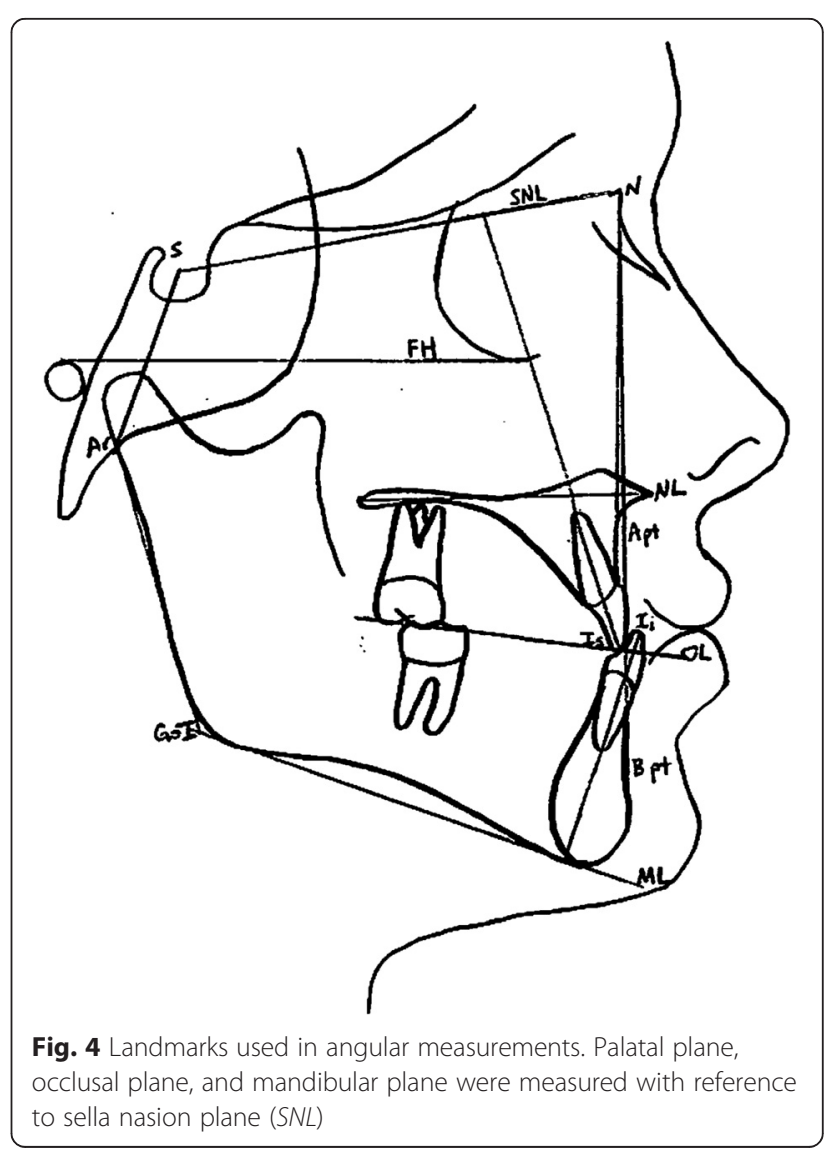


Table 2 Calculation of changes in overjet and molar relationship

\begin{tabular}{ll}
\hline Overjet & Molar relationship \\
\hline Skeletal contribution & Skeletal contribution \\
1. OLp-A pt. & 1. OLp-A pt. \\
2. OLp-Pg & 2. OLp-Pg \\
Dental contribution & Dental contribution \\
3. OLp-Is minus OLp-A pt. & 3. OLp-Ms minus OLp-A pt. \\
4. OLp-li minus OLp-Pg & 4. OLp-Mi minus OLp-Pg \\
Overjet correction & Molar relationship correction \\
Sum of 1, 2, 3, and 4 & Sum of 1, 2, 3, and 4 \\
\hline
\end{tabular}

Medical Solutions, Tuttlingen, Germany) were placed in the anterior palate, in the area of the third palatal rugae. Transfer caps were added before a silicone impression was taken. Laboratory analogs were placed over the transfer caps, bands were positioned in the impression, and a plaster cast is made. Two standard Benefit abutments were screwed over the laboratory analogs. A Hyrax-type (Trademark of Dentaurum, Inc., Newtown, PA) palatal split screw was welded or soldered to the two anterior abutments and to the molar bands. The jackscrew was activated twice daily $(0.25 \mathrm{~mm}$ per turn) by the patient for 1 week. In patients with a constricted maxilla, activation of the expansion screw was applied for 2 weeks. Rigid .048-in. stainless steel sectional wires with hooks near the canines are welded or soldered to the buccal sides of the molar bands for the application of orthopedic protraction forces.

Table 3 Sagittal, vertical, and angular measurements in the control group

\begin{tabular}{|c|c|c|c|c|c|c|c|c|c|}
\hline \multirow{2}{*}{$\begin{array}{l}\text { Variables (mm) } \\
\text { Sagittal }\end{array}$} & \multicolumn{4}{|l|}{ TO } & \multicolumn{4}{|l|}{$\mathrm{T} 1$} & \multirow{2}{*}{$\begin{array}{l}\text { T1 - T0 } \\
\text { Diff }\end{array}$} \\
\hline & Mean & SD & Min & Max & Mean & SD & Min & Max & \\
\hline OLp-A pt. & 67.27 & 3.73 & 60.19 & 74.21 & 68.06 & 3.90 & 60.58 & 75.17 & 0.80 \\
\hline OLp-B pt. & 75.74 & 4.86 & 68.45 & 82.66 & 76.74 & 4.96 & 69.02 & 83.23 & 1.00 \\
\hline OLp-Pg & 77.11 & 5.47 & 69.12 & 85.54 & 78.18 & 5.53 & 69.60 & 87.26 & 1.08 \\
\hline Wits & -8.52 & 3.10 & -13.44 & -2.50 & -8.26 & 3.11 & -13.63 & -2.88 & 0.27 \\
\hline OLp-Is & 74.17 & 4.68 & 62.40 & 80.74 & 75.49 & 4.92 & 63.55 & 83.90 & 1.32 \\
\hline OLp-li & 76.26 & 4.78 & 63.94 & 82.75 & 77.48 & 4.95 & 65.86 & 85.63 & 1.22 \\
\hline Overjet & -2.09 & 0.98 & -4.03 & 0.38 & -1.99 & 0.90 & -4.22 & 0.00 & 0.11 \\
\hline OLp-Ms & 48.05 & 4.35 & 40.13 & 54.82 & 49.30 & 4.49 & 40.99 & 55.97 & 1.25 \\
\hline OLp-Mi & 51.58 & 5.68 & 42.72 & 60.58 & 52.80 & 5.79 & 42.72 & 62.21 & 1.22 \\
\hline Molar relationship & -3.57 & 2.39 & -7.97 & 0.48 & -3.47 & 2.20 & -7.87 & -0.58 & 0.11 \\
\hline \multicolumn{10}{|l|}{ Vertical (mm) } \\
\hline OLparallel-A pt. & 20.35 & 38.78 & 29.59 & 5.89 & 23.81 & 40.42 & 31.47 & 5.62 & 1.88 \\
\hline $\mathrm{Is}-\mathrm{NL}$ & 20.26 & 29.86 & 24.91 & 2.69 & 20.64 & 30.62 & 25.74 & 2.61 & 0.83 \\
\hline $\mathrm{Ii}-\mathrm{ML}$ & 33.60 & 41.18 & 37.61 & 2.14 & 34.27 & 43.01 & 38.28 & 2.45 & 0.66 \\
\hline Overbite & 0.00 & 10.46 & 3.01 & 2.56 & 0.00 & 9.02 & 3.32 & 2.36 & 0.31 \\
\hline Msc-NL & 13.25 & 22.46 & 18.97 & 2.05 & 16.32 & 22.75 & 19.44 & 1.54 & 0.47 \\
\hline Mic-ML & 25.06 & 30.91 & 28.32 & 1.46 & 26.30 & 30.62 & 28.62 & 1.25 & 0.30 \\
\hline \multicolumn{10}{|l|}{ Angular $\left({ }^{\circ}\right)$} \\
\hline SNA & 73.63 & 81.60 & 78.57 & 2.59 & 73.82 & 82.75 & 78.85 & 2.85 & 0.29 \\
\hline SNB & 73.82 & 83.04 & 78.75 & 2.92 & 74.02 & 83.42 & 79.27 & 2.76 & 0.52 \\
\hline ANB & -3.74 & 3.55 & -0.18 & 2.09 & -3.65 & 3.07 & -0.41 & 2.02 & -0.23 \\
\hline SNL-ML & 24.00 & 37.44 & 32.58 & 4.54 & 23.42 & 38.21 & 32.09 & 4.59 & -0.49 \\
\hline SNL-OL & 12.48 & 28.80 & 20.17 & 5.40 & 12.58 & 27.94 & 19.96 & 4.99 & -0.21 \\
\hline SNL-NL & 3.36 & 12.58 & 8.62 & 3.02 & 1.73 & 12.38 & 7.88 & 3.21 & -0.74 \\
\hline IS-SNL & 85.73 & 117.31 & 100.78 & 8.62 & 87.36 & 116.54 & 103.17 & 8.31 & 2.39 \\
\hline $\mathrm{li}-\mathrm{ML}$ & 64.99 & 100.90 & 87.30 & 8.28 & 68.93 & 102.72 & 86.75 & 9.18 & -0.56 \\
\hline
\end{tabular}


The facemask was a one-piece construction with an adjustable anterior wire and hooks to accommodate a downward and forward pull of the maxilla with elastics. The protraction elastics were attached near the maxillary canines with a downward and forward pull of $30^{\circ}$ to the occlusal plane. Maxillary protraction generally requires an orthopedic force of 300-600 g per side depending on the age of the patient. In the present study, elastics that delivered $380 \mathrm{~g}$ per side as measured by a force gauge were used. The patients were instructed to wear the facemask for $12-14 \mathrm{~h}$ a day.

\section{Cephalometric analysis}

Pre- and post-treatment lateral cephalograms were digitized and calibrated using the Dolphin Imaging software (Dolphin Imaging, Chatsworth, CA, USA). A customized cephalometric system incorporating measurements from Bjork [35] and Pancherz [36] for the sagittal and vertical variables and Steiner, Tweed, and McNamara analyses for the angular variables were used to determine treatment changes. The landmarks used are shown in Figs. 2, 3, and 4. The magnification factor of the lateral cephalograms was found to be $6 \%$ for both the control and the tooth-borne treatment groups. There was no magnification factor for the digital radiographs of the bone-borne treatment group. The sagittal and vertical variables were reported in millimeters and were recorded to the nearest $0.1 \mathrm{~mm}$. Angular measurements were reported to the nearest $0.1^{\circ}$. Films were printed 1:1 using a Kodak ESP 7250 printer (Kodak, Atlanta, GA, USA) and then traced by one investigator using a $0.5 \mathrm{~mm}$ mechanical lead pencil, $3 \mathrm{M}$ Unitek orthodontic protractor (Monrovia, $\mathrm{CA}$ ), and 0.003 in. matte $3 \mathrm{M}$ Unitek cephalometric acetate tracing film (Monrovia, CA). All radiographs were

Table 4 Sagittal, vertical, and angular measurements for the tooth-borne protraction facemask group

\begin{tabular}{|c|c|c|c|c|c|c|c|c|c|}
\hline \multirow{2}{*}{$\begin{array}{l}\text { Variables (mm) } \\
\text { Sagittal }\end{array}$} & \multicolumn{4}{|l|}{$\mathrm{T} 1$} & \multicolumn{4}{|l|}{$\mathrm{T} 2$} & \multirow{2}{*}{$\begin{array}{l}\text { T2-T1 } \\
\text { Diff }\end{array}$} \\
\hline & Min & Max & Mean & SD & Min & Max & Mean & SD & \\
\hline OLp-A pt. & 60.58 & 75.17 & 68.06 & 3.90 & 60.77 & 75.94 & 69.59 & 4.26 & 1.53 \\
\hline OLp-B pt. & 69.02 & 83.23 & 76.74 & 4.96 & 66.62 & 82.46 & 75.41 & 4.86 & -1.33 \\
\hline OLp-Pg & 69.60 & 87.26 & 78.18 & 5.53 & 66.34 & 85.15 & 77.14 & 5.58 & -1.05 \\
\hline Wits & -13.63 & -2.88 & -8.26 & 3.11 & -9.12 & 1.63 & -5.74 & 3.23 & 2.52 \\
\hline OLp-ls & 63.55 & 83.90 & 75.49 & 4.92 & 69.98 & 87.26 & 78.99 & 4.46 & 3.49 \\
\hline OLp-li & 65.86 & 85.63 & 77.48 & 4.95 & 66.72 & 80.83 & 75.22 & 4.29 & -2.27 \\
\hline Overjet & -4.22 & 0.00 & -1.99 & 0.90 & 0.00 & 8.74 & 3.77 & 2.17 & 5.76 \\
\hline OLp-Ms & 40.99 & 55.97 & 49.30 & 4.49 & 44.74 & 61.54 & 51.94 & 4.86 & 2.64 \\
\hline OLp-Mi & 42.72 & 62.21 & 52.80 & 5.79 & 43.68 & 60.67 & 52.70 & 5.11 & -0.12 \\
\hline Molar relationship & -7.87 & -0.58 & -3.47 & 2.20 & -5.66 & 1.73 & -0.75 & 2.06 & 2.72 \\
\hline \multicolumn{10}{|l|}{ Vertical (mm) } \\
\hline OLparallel-A pt. & 23.81 & 40.42 & 31.47 & 5.62 & 26.11 & 45.98 & 34.54 & 5.24 & 3.07 \\
\hline $\mathrm{Is}-\mathrm{NL}$ & 20.64 & 30.62 & 25.74 & 2.61 & 21.02 & 30.34 & 26.03 & 2.52 & 0.29 \\
\hline $\mathrm{li}-\mathrm{ML}$ & 34.27 & 43.01 & 38.28 & 2.45 & 35.42 & 42.82 & 39.02 & 1.91 & 0.75 \\
\hline Overbite & 0.00 & 9.02 & 3.32 & 2.36 & 0.00 & 3.84 & 2.08 & 1.07 & -1.24 \\
\hline Msc-NL & 16.32 & 22.75 & 19.44 & 1.54 & 17.38 & 23.33 & 20.74 & 1.96 & 1.30 \\
\hline Mic-ML & 26.30 & 30.62 & 28.62 & 1.25 & 27.07 & 31.87 & 29.60 & 1.47 & 0.98 \\
\hline \multicolumn{10}{|l|}{ Angular ( $\left.{ }^{\circ}\right)$} \\
\hline SNA & 73.82 & 82.75 & 78.85 & 2.85 & 75.36 & 84.19 & 79.55 & 2.78 & 0.69 \\
\hline SNB & 74.02 & 83.42 & 79.27 & 2.76 & 72.77 & 81.41 & 77.54 & 2.28 & -1.73 \\
\hline ANB & -3.65 & 3.07 & -0.41 & 2.02 & -2.59 & 6.34 & 2.01 & 2.54 & 2.42 \\
\hline SNL-ML & 23.42 & 38.21 & 32.09 & 4.59 & 27.36 & 41.38 & 34.43 & 4.17 & 2.33 \\
\hline SNL-OL & 12.58 & 27.94 & 19.96 & 4.99 & 11.04 & 24.10 & 17.98 & 4.20 & -1.98 \\
\hline SNL-NL & 1.73 & 12.38 & 7.88 & 3.21 & 4.51 & 12.00 & 7.89 & 2.04 & 0.01 \\
\hline IS-SNL & 87.36 & 116.54 & 103.17 & 8.31 & 94.94 & 113.47 & 105.36 & 6.44 & 2.19 \\
\hline $\mathrm{li}-\mathrm{ML}$ & 68.93 & 102.72 & 86.75 & 9.18 & 72.96 & 96.00 & 81.75 & 7.09 & -4.99 \\
\hline
\end{tabular}


traced by one person (N.D.) who was blinded to the treatment groups to avoid bias to cephalometric tracing. Analysis of the sagittal skeletal and dental changes were recorded along the occlusal plane (OL) and to the occlusal plane perpendicular (OLp) from the first film, this formed the reference grid. The grid was then transferred to a subsequent film by superimposing the tracing on the mid-sagittal cranial structures. The changes in overjet and molar relationship were calculated using the formula depicted in (Table 2) using the formula depicted in Table 3.

\section{Data analysis}

The statistical analysis was carried out utilizing the JMP version 90.9 SAS Software (Cary, NC). The starting forms of the control and experimental samples were compared using a two-tailed $t$ test. The skeletal and dental changes between the treated and control sample at the two time periods were compared with a two-tailed $t$ test. The confidence level was set at $95 \%$.

\section{Method error}

The error in locating, superimposing, and measuring the changes of the landmarks by one examiner was measured on the cephalograms of 10 randomly selected subjects. All cephalograms were recorded twice independently on two separate occasions with a 2-week interval. For all the cephalometric variables, difference between the independent repeated measurements of each individual before/after treatment was recorded. The intraclass correlation coefficient of reliability $(R)$ was used to determine the reliability of cephalometric measurements. The $R$ value can range from 0 to 1.00 with $R$ value greater than 0.90 indicating high reliability. The correlations of all the cephalometric variables ranged from 0.96 to 0.99 , with most being above 0.98 . The method

Table 5 Sagittal, vertical, and angular measurements for the bone-anchored protraction facemask group

\begin{tabular}{|c|c|c|c|c|c|c|c|c|c|}
\hline \multirow{2}{*}{$\begin{array}{l}\text { Variables (mm) } \\
\text { Sagittal }\end{array}$} & \multicolumn{4}{|l|}{$\mathrm{T} 1$} & \multicolumn{4}{|l|}{$\mathrm{T} 2$} & \multirow{2}{*}{$\begin{array}{l}\text { T2-T1 } \\
\text { Diff }\end{array}$} \\
\hline & Min & Max & Mean & SD & Min & Max & Mean & SD & \\
\hline OLp-A pt. & 60.0 & 76.9 & 66.74 & 3.93 & 61.9 & 78.7 & 68.28 & 4.32 & 1.54 \\
\hline OLp-B pt. & 63.5 & 80.0 & 71.86 & 5.13 & 62.8 & 80.6 & 70.57 & 5.41 & -1.29 \\
\hline OLp-Pg & 66.7 & 84.0 & 73.95 & 4.70 & 65.8 & 84.1 & 73.82 & 5.11 & -0.13 \\
\hline Wits & -9.6 & 0.2 & -5.12 & 2.58 & -6.9 & 6.9 & -2.54 & 3.22 & 2.58 \\
\hline OLp-Is & 60.1 & 79.3 & 70.28 & 4.67 & 60.3 & 84.4 & 72.47 & 5.57 & 2.19 \\
\hline OLp-li & 61.9 & 79.0 & 71.14 & 4.67 & 55.4 & 80.9 & 69.88 & 5.52 & -1.26 \\
\hline Overjet & -4.8 & 2.9 & -0.86 & 2.31 & -1.6 & 5.9 & 2.6 & 1.76 & 3.46 \\
\hline OLp-Ms & 40.2 & 50.7 & 44.45 & 3.18 & 41.1 & 58.0 & 46.89 & 4.27 & 2.44 \\
\hline OLp-Mi & 41.3 & 55.2 & 47.52 & 4.20 & 42.2 & 59.1 & 48.94 & 4.65 & 1.42 \\
\hline Molar relationship & -0.6 & -7.0 & -3.34 & 1.65 & -4.9 & 0.4 & -2.05 & 1.62 & 1.29 \\
\hline \multicolumn{10}{|l|}{ Vertical (mm) } \\
\hline OLparallel-A pt. & 16.4 & 38.9 & 30.14 & 5.43 & 16.5 & 41.3 & 31.62 & 6.07 & 1.48 \\
\hline $\mathrm{Is}-\mathrm{NL}$ & 14.4 & 27.7 & 22.41 & 3.69 & 19.9 & 29.0 & 24.58 & 2.61 & 2.17 \\
\hline $\mathrm{li}-\mathrm{ML}$ & 27.9 & 39.9 & 34.82 & 3.45 & 29.7 & 41.2 & 36.08 & 3.11 & 1.26 \\
\hline Overbite & -1.1 & 5.9 & 1.56 & 2.18 & -1.8 & 4.4 & 1.42 & 1.48 & -0.14 \\
\hline Msc-NL & 9.1 & 21.9 & 17.02 & 3.00 & 11.8 & 22.9 & 18.58 & 2.73 & 1.56 \\
\hline Mic-ML & 23.3 & 30.5 & 26.51 & 2.06 & 23.9 & 32.9 & 27.7 & 2.13 & 1.19 \\
\hline \multicolumn{10}{|l|}{ Angular $\left({ }^{\circ}\right)$} \\
\hline SNA & 71.9 & 92.1 & 80.29 & 4.74 & 73.0 & 91.2 & 81.88 & 4.49 & 1.59 \\
\hline SNB & 74.8 & 90.2 & 81.2 & 4.17 & 71.9 & 88.8 & 80.4 & 4.25 & -0.8 \\
\hline ANB & -5.5 & 3.3 & -0.92 & 2.78 & -3.8 & 6.9 & 1.48 & 2.76 & 2.4 \\
\hline SNL-ML & 22.2 & 44.9 & 32.62 & 6.07 & 21.1 & 49.5 & 32.86 & 7.13 & 0.24 \\
\hline SNL-OLS & 9.0 & 29.4 & 18.14 & 5.89 & 7.2 & 32.0 & 17.31 & 6.09 & -0.83 \\
\hline SNL-NL & 2.6 & 12.9 & 6.44 & 3.07 & 1.1 & 14.0 & 6.52 & 3.68 & 0.08 \\
\hline Is-SNL & 87.2 & 121.8 & 103.19 & 8.23 & 86.8 & 114.2 & 101.16 & 8.12 & -2.03 \\
\hline li-ML & 78.1 & 91.9 & 84.75 & 3.48 & 77.8 & 95.6 & 83.08 & 4.54 & -1.67 \\
\hline
\end{tabular}


Table 6 Comparison of differences between the tooth-borne and bone-anchored groups after subtracting changes due to growth (control group)

\begin{tabular}{|c|c|c|c|c|c|c|}
\hline \multirow{2}{*}{$\begin{array}{l}\text { Variables } \\
\text { Sagittal }\end{array}$} & \multicolumn{2}{|c|}{ Tooth-borne protraction facemask } & \multicolumn{2}{|c|}{ Bone-anchored protraction facemask } & \multirow[b]{2}{*}{$p$ value } & \multirow[b]{2}{*}{ Sic } \\
\hline & Mean & SD & Mean & SD & & \\
\hline OLp-A pt. & 0.72 & 1.29 & 0.74 & 1.23 & 0.98 & NS \\
\hline OLp-B pt. & -2.28 & 1.43 & -2.31 & 2.15 & 0.93 & NS \\
\hline OLp-Pg & -2.07 & 2.11 & -1.21 & 3.05 & 0.32 & NS \\
\hline Wits & 2.19 & 2.74 & 2.31 & 2.40 & 0.89 & NS \\
\hline OLp-Is & 2.12 & 1.22 & 0.87 & 2.43 & 0.03 & * \\
\hline OLp-li & -3.40 & 2.33 & -2.48 & 2.26 & 0.23 & NS \\
\hline Overjet & 5.53 & 2.00 & 3.35 & 2.45 & 0.003 & * \\
\hline OLp-Ms & 1.35 & 1.53 & 1.19 & 1.78 & 0.67 & NS \\
\hline OLp-Mi & -1.31 & 0.55 & 0.20 & 2.93 & 0.06 & NS \\
\hline Molar relationship & 2.53 & 1.55 & 1.18 & 1.99 & 0.02 & $*$ \\
\hline \multicolumn{7}{|l|}{ Vertical (mm) } \\
\hline OLparallel-A pt & 1.15 & 2.00 & -0.40 & 1.40 & 0.004 & * \\
\hline Is-NL & -0.52 & 1.50 & 1.34 & 2.80 & 0.01 & * \\
\hline $\mathrm{li}-\mathrm{ML}$ & 0.09 & 2.18 & 0.60 & 1.72 & 0.49 & NS \\
\hline Overbite & -1.49 & 2.90 & -0.45 & 2.23 & 0.21 & NS \\
\hline Msc-NL & 0.80 & 1.56 & 1.09 & 1.86 & 0.63 & NS \\
\hline Mic-ML & 0.66 & 1.36 & 0.89 & 1.38 & 0.62 & NS \\
\hline \multicolumn{7}{|l|}{ Angular ( $\left(^{\circ}\right)$} \\
\hline SNA & 0.39 & 1.74 & 1.29 & 2.13 & 0.15 & NS \\
\hline SNB & -2.19 & 1.51 & -1.32 & 1.99 & 0.13 & NS \\
\hline ANB & 2.58 & 1.80 & 2.17 & 2.41 & 0.95 & NS \\
\hline $\mathrm{SNL}-\mathrm{ML}$ & 2.76 & 1.39 & -0.25 & 2.90 & 0.007 & * \\
\hline $\mathrm{SNL}-\mathrm{OL}$ & -1.73 & 3.90 & -1.04 & 3.33 & 0.33 & NS \\
\hline $\mathrm{SNL}-\mathrm{NL}$ & 0.72 & 2.72 & -0.66 & 2.15 & 0.87 & NS \\
\hline Is-SNL & -0.19 & 7.35 & -4.42 & 5.67 & 0.04 & * \\
\hline $\mid \mathrm{i}-\mathrm{ML}$ & -4.33 & 7.68 & -2.23 & 3.84 & 0.09 & NS \\
\hline
\end{tabular}

NS not significantly different

*Significantly different at $p<0.05$

of cephalometric analysis used in this study was deemed reliable and repeatable.

\section{Results}

\section{Cephalometric changes}

Changes in cephalometric measurements in the control group and patients treated with the tooth-borne and bone-borne protraction facemask are shown in Tables 3, 4 , and 5 . The appliance effect was calculated by subtracting the changes due to growth (control group) from the treatment changes (Table 6).

\section{Sagittal and angular differences}

Significant differences between the tooth-borne and bone-anchored protraction facemask groups were found in three of the 10 sagittal and angular variables. Figures 5, 6, 7, and 8 summarize the skeletal and dental contributions to the overjet and molar correction from treatment.

For both treatment groups, all subjects were overcorrected to a class I or class II molar relationship. Significant and greater change in overjet was found in the tooth-borne group $(5.5 \mathrm{~mm})$ compared to the boneanchored group $(3.4 \mathrm{~mm}, p<.001)$. This was contributed by similar forward movement of the maxilla (OLp-A pt., $0.7 \mathrm{~mm}$ ) and backward movement of the mandible (OLp-Pg, $2.2 \mathrm{~mm}$ ) in both groups, but greater forward movement of the maxillary incisors was found in the tooth-borne group (OLp-Is 2.12 vs. $0.87 \mathrm{~mm}, p<.05)$. 


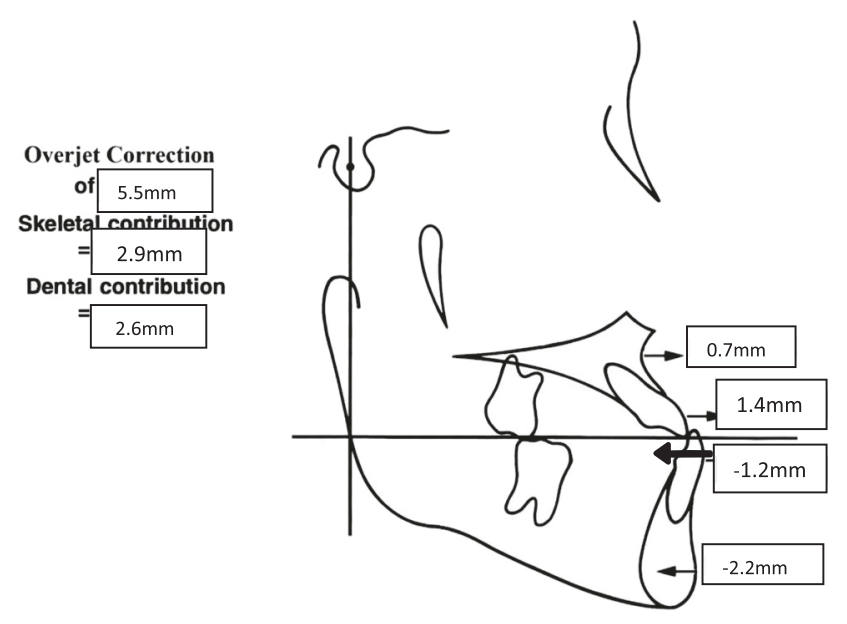

Maxilla $=$ OLp-A pt. (0.7)

Maxillary incisor $=$ OLp-Is $(2.1 \mathrm{~mm})$ minus OLp-A pt. $(0.7 \mathrm{~mm})=1.4 \mathrm{~mm}$

Mandible $=$ OLp-Pg (-2.2)

Mandibular incisor $=\mathrm{OLp}-\mathrm{li}(-3.4 \mathrm{~mm})$ minus OLp-Pg $(-2.2 \mathrm{~mm})=-1.2 \mathrm{~mm}$

Overjet Correction $=$ Maxilla $(0.7 \mathrm{~mm})+\mathrm{Mx}$ incisor $(1.4 \mathrm{~mm})-$ Mandible $(-2.2 \mathrm{~mm})-$ Md incisor $(-1.2 \mathrm{~mm})$

$=5.5 \mathrm{~mm}$.

Fig. 5 Skeletal and dental contributions to overjet correction for the tooth-borne protraction facemask group

Significant and greater change in molar relationship was found in the tooth-borne group $(2.7 \mathrm{~mm})$ compared to the bone-anchored group $(1.1 \mathrm{~mm}, p<.05)$. This was contributed by similar forward movement of the maxilla and backward movement of the mandible in both groups, but greater differential movement of the maxillary and mandibular molars was found in the tooth-borne protraction facemask group. The mean forward movement of maxillary molars was similar for the tooth-borne $(0.6 \mathrm{~mm})$ and bone-anchored protraction facemask groups $(0.5 \mathrm{~mm})$.

The anteroposterior jaw relationship was improved in both the tooth-borne group (Wits $2.19 \mathrm{~mm}$, ANB $2.58^{\circ}$ ) and the bone-anchored group (Wits $2.31 \mathrm{~mm}$, ANB $\left.2.17^{\circ}\right)$.

\section{Vertical and angular differences}

Significant differences between the tooth-borne and bone-anchored protraction facemask groups were found in five of the 14 vertical and angular variables. Significantly greater downward movement of the maxilla was found in the tooth-borne (OLparallel-A pt. $1.2 \mathrm{~mm}$ ) compared to the bone-anchored protraction facemask group $(-0.4 \mathrm{~mm}, p<.005)$. The mandibular plane angle was found to open significantly more in the tooth-borne group (SNL-ML 2.76 ${ }^{\circ}$ compared to the bone-anchored protraction facemask group $\left(-0.25^{\circ}, 0.23^{\circ}, p<.05\right)$. Significantly greater downward movement and retroclination of the maxillary incisors was found in the bone-anchored group (Is-NL $1.34 \mathrm{~mm}$, Is-SNL $-4.42^{\circ}$ ) compared to the tooth-borne group $\left(-0.55 \mathrm{~mm},-0.19^{\circ}, p<.05\right)$.

\section{Discussion}

Maxillary protraction using both the tooth-borne RPE and RPE reinforced by two mini-implants were able to correct the anterior crossbite and improve the molar relationship in around 6 months. This was contributed by a forward and downward movement of the maxilla, clockwise rotation of the mandible, proclination of the maxillary incisors, and retroclination of the mandibular incisors. The maxilla articulates with nine other bones of the craniofacial complex: frontal, nasal, lacrimal, ethmoid, palatine, vomer, zygoma, inferior nasal concha, opposite maxilla, and occasionally, sphenoid. Palatal expansion may "disarticulate" the maxilla and initiate cellular response in the sutures, allowing a more positive reaction to protraction forces [12, 13, 37]. In this study, the maxilla moved forward an average of $1.5 \mathrm{~mm}$, or $0.7 \mathrm{~mm}$ after subtracting changes due to growth, with both the tooth-borne and bone-anchored protraction facemask treatment. This is in line with those reported by Nanda [38], Ishii [39], Merwin [40], and Turley [12]. 


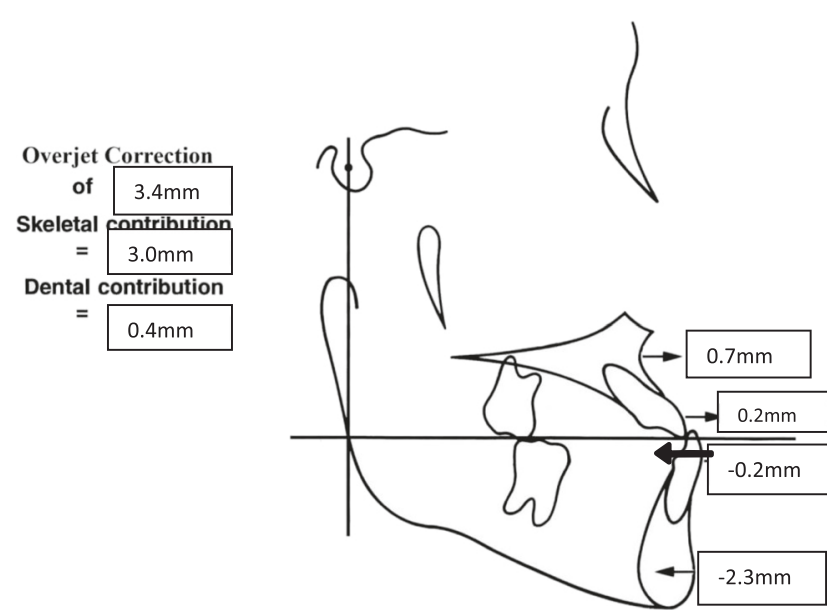

Maxilla $=$ OLp-A pt $(0.7 \mathrm{~mm})$

Maxillary incisor $=$ OLp-Is $(0.9 \mathrm{~mm})$ minus OLp-A pt. $(0.7)=0.2 \mathrm{~mm}$

Mandible $=\mathrm{OLp}-\mathrm{Pg}(-2.3 \mathrm{~mm})$

Mandibular incisor $=\mathrm{OLp}-\mathrm{li}(-2.5 \mathrm{~mm})$ minus OLp-Pg $(-2.3 \mathrm{~mm})=-0.2 \mathrm{~mm}$

Overjet Correction= Maxilla $(0.7 \mathrm{~mm})+$ Mx incisor $(0.2 \mathrm{~mm})-$ Mandible $(-2.3 \mathrm{~mm})-$ Md incisor $(-0.2 \mathrm{~mm})$

$=3.4 \mathrm{~mm}$.

Fig. 6 Skeletal and dental contributions to overjet correction for the bone-anchored protraction facemask group
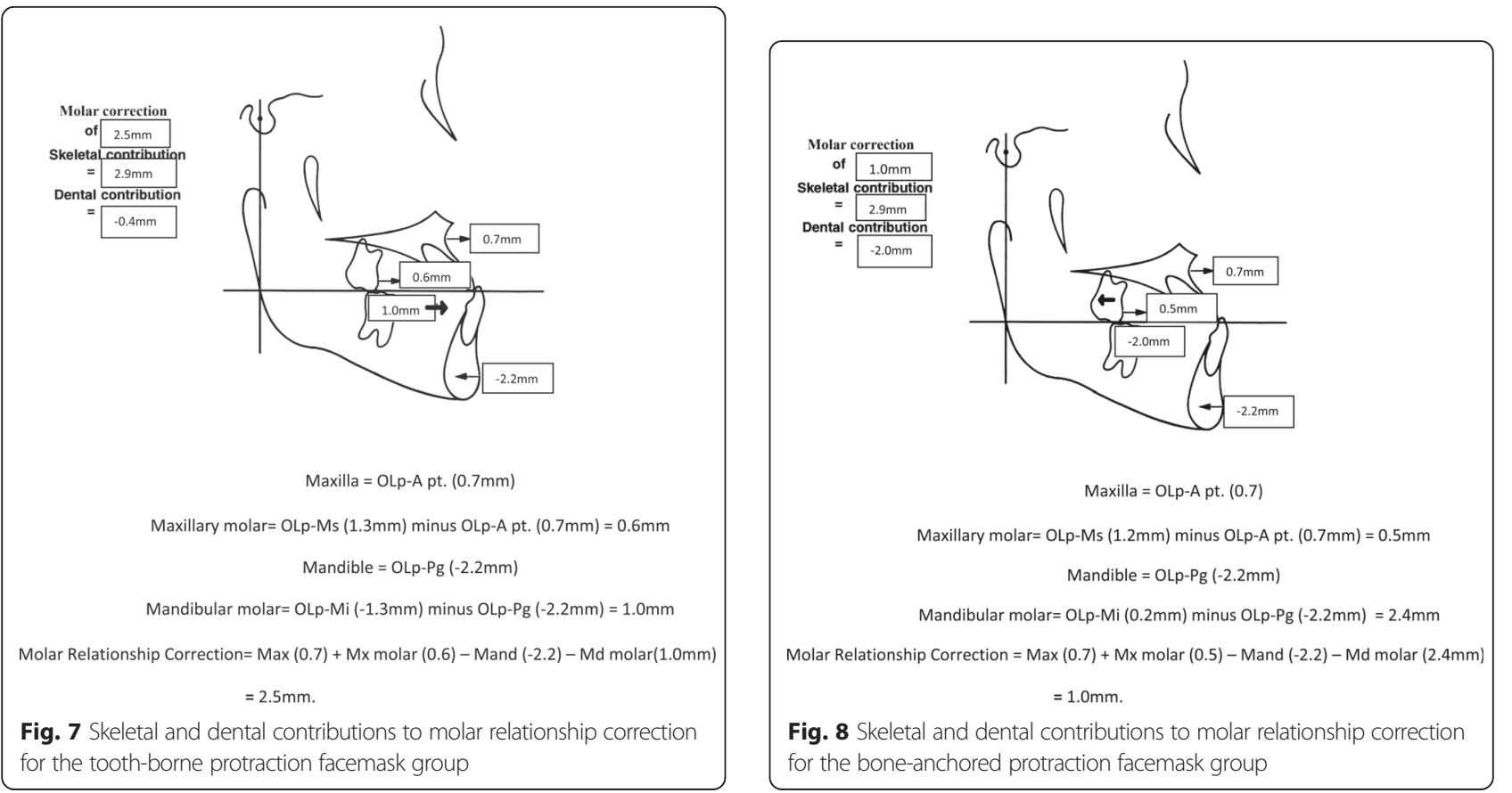
However, Cevidanes et al. reported larger maxillary advancement with their bone-anchored maxillary protraction (BAMP) compared to conventional RPE [29]. This is probably related to the full-time wear of class III elastics compared to smaller number of hours with the facemask. The maxillary incisors were found to move forward more in the tooth-borne compared to the bone-anchored protraction facemask group, resulting in greater increase in the overjet in the latter group. This may be due to the anchorage provided by the two miniimplants. The maxillary molars were found to move forward an average of $0.6 \mathrm{~mm}$ in the bone-anchored groups despite the anchorage provided by the two miniimplants. This is in line with those reported by Wilmes et al. [32,33] with the Hybrid Hyrax appliance and other investigators that used bone-anchored devices for maxillary protraction [19-21, 27-30]. This small amount of mesial molar movement is probably due to wire bending rather than movement of the mini-implants.

For vertical changes, the mandible was found to move backward in both the tooth-borne and bone-anchored groups (SNB $-2.2^{\circ}$ and $-1.3^{\circ}$, respectively). This, together with the forward movement of the maxilla, contributed to the improvement in the Wits appraisal and ANB changes in both groups. However, the downward movement of the maxilla in the latter group was significantly less. The incorporation of two mini-implants helps in minimizing the downward movement of the maxilla and consequently the clockwise rotation of the mandible in the bone-anchored group (SNL-ML 0.7 for the bone-anchored group vs. SNL-ML $2.9^{\circ}$ for the tooth-borne group, $p<.05)$. This is also in line with those reported by investigators using bone-anchored devices for maxillary protraction [19-21, 27-33]. In addition, there is more downward movement of the maxillary incisors in the bone-anchored group compared to the tooth-borne group that helps to maintain the overbite in the bone-anchored group.

There are several limitations to the design of this study. This is a retrospective study and the patients were treated by two different operators, one for the toothborne patients and one for the bone-borne patients. The radiographs of the two treatment groups were taken from different lateral cephalometric machines but they were adjusted for magnification. The control radiographs were selected from class III patients who were under growth observation, and efforts were made to match the age, sex, and craniofacial morphology as closely as possible. Finally, the results from this study are limited to a short-term observation period immediately after active treatment; long-term studies are needed for the appraisal of the stability of protraction with the Hybrid Hyrax appliance and compared to the long-term results of conventional RPE and facemask treatment [14].

\section{Conclusions}

The addition of two mini-implants in the Hybrid Hyrax RPE minimized the side effects encounter by toothborne RPE for maxillary protraction such as excessive forward movement of the maxillary molars and incisors, downward movement of the maxilla, and clockwise rotation of the mandible. This appliance may serve as an alternative treatment appliance for correcting class III patients with a hyperdivergent growth pattern.

\section{Competing interests}

The authors declared that they have no competing interests.

\section{Authors' contributions}

PN designed and edited the manuscript. BW and DD participated in treatment of implant patients used in the study; CM collected the data and prepared for analysis; BW analyzed the data and prepared a draft of the manuscript; EG performed the statistical analysis of the data. All authors read and approved the final manuscript.

\section{Acknowledgement}

We would like to acknowledge Dr. Nicole DeShon for her help in the tracing of the cephalometric radiographs.

\section{Author details}

'Department of Orthodontics, School of Dentistry, West Virginia University, 1073 Health Science Center North, P.O. Box 9480, Morgantown, WV 26506, USA. ${ }^{2}$ Department of Orthodontics, University of Düsseldorf, Moorenstrasse, Germany. ${ }^{3}$ Department of Oral and Maxillofacial Surgery, School of Dentistry, West Virginia University, Morgantown, USA. ${ }^{4}$ Department of Statistics, West Virginia University, Morgantown, USA.

Received: 1 July 2015 Accepted: 4 August 2015

Published online: 25 August 2015

\section{References}

1. Chatzoudi MI, Loannidou-Marathiotou L, Papadopoulos MA. Clinical effectiveness of chin cup treatment for the management of class III malocclusion in pre-pubertal patients: a systematic review and metaanalysis. Prog Orthod. 2014;15:62.

2. Tollaro I, Baccetti T, Bassarelli V, Franchi L. Class III malocclusion in the deciduous dentition: a morphological and correlation study. Eur J Orthod. 1994; 16:401-8

3. VanLaecken R, Williams MO, Razmus T, Gunel E, Martin C, Ngan P. Class III correction using an inter-arch spring-loaded module. Prog Orthod. 2014;15:32.

4. Kajiyama K, Murakami T, Suzuki A. Evaluation of the modified maxillary protractor applied to class III malocclusion with retruded maxilla in early mixed dentition. Am J Orthod Dentofac Orthop. 2000;5:549-59.

5. Reed E, Kiebach T, Ngan P, Martin C, Razmus T, Gunel E. Stability of early class III orthopedic treatment in the primary and early mixed dentitions. Sem in Orthod. 2014;20:114-27.

6. Sakamoto T. Effective timing for the application of orthopedic force in the skeletal class III malocclusion. Am J Orthod. 1981;80:411-6.

7. Mermigos J, Full CA, Andreasen G. Protraction of the maxillofacial complex. Am J Orthod Dentofac Orthop. 1990;98:127-33.

8. Benedetti M, Bosch C, Melsen B. Changes occurring during and after treatment of class III malocclusion with rapid palatal expansion and facemask. World J Orthod. 2002;3:199-210

9. Ngan PW, Hagg U, Yiu C, Wei SHY. Treatment response and long-term dentofacial adaptations to maxillary expansion and protraction. Seminars in Orthod. 1997:4:255-64.

10. Baccetti T, Franchi L, McNamara Jr JA. Treatment and post-treatment craniofacial changes after rapid maxillary expansion and facemask therapy. Am J Orthod Dentofac Orthop. 2000;118:404-13.

11. Saadia M, Torres E. Sagittal changes after maxillary protraction with expansion in class III patients in the primary, mixed and late mixed 
dentitions: a longitudinal retrospective study. Am J Orthod Dentofac Orthop. 2000;117:669-80.

12. Nartallo-Turley PE, Turley PK. Cephalometric effects of combined palatal expansion and facemask therapy on class III malocclusion. Angle Orthod. 1998;68(3):217-24

13. Liou EJ. Effective maxillary orthopedic protraction for growing class III patients: a clinical application simulates distraction osteogenesis. Prog Orthod. 2005;6(2):154-71.

14. Hagg U, Tse A, Bendeus M, Rabie BM. Long-term follow-up of early treatment with reverse headgear. Eur J Orthod. 2003:25:95-102.

15. Lertpitayakun P, Miyajima K, Kanomi R, Sinha PK. Cephalometric changes after long-term early treatment with facemask and maxillary intraoral appliance therapy. Sem in Orthod. 2001;7:169-79.

16. Delaire J. Maxillary development revisited: relevance to the orthopaedic treatment of class III malocclusions. Eur J Orthod. 1997;19:289-311.

17. da Silva Filho OG, Magro AC, Capelozza FL. Early treatment of the class III malocclusion with rapid maxillary expansion and maxillary protraction. Am J Orthod Dentofac Orthop. 1998;113(2):196-203. doi:10.1016/S0889-5406(98)70292-6.

18. Kokich VG, Shapiro PA, Oswald R, Koskinen-Moffett L, Clarren SK. Ankylosed teeth as abutments for maxillary protraction: a case report. Journal Orthod. 1985;88:303-7.

19. Cha B, Choi D, Ngan $P$, Jost-Brinkmann $P$, Kim S, Jang I. Maxillary protraction with miniplates providing skeletal anchorage in a growing class III patient. Am J Orthod Dentofac Orthop. 2011;139(1):99-112. doi:10.1016/ j.ajodo.2009.06.025.

20. Singer S. Osseointegrated implants as an adjunct to facemask therapy: a case report. Angle Orthod. 2000;70(3):253.

21. Hong H, Ngan P, Han GL, Liu GQ, Wei SHY. Use of onplants as stable anchorage for facemask treatment: a case report. Angle Orthod. 2005;75(3):453-60

22. Enacar A, Giray B, Pehlivanoglu M, Iplikcioglu H. Facemask therapy with rigid anchorage in a patient with maxillary hypoplasia and severe oligodontia. Am J Orthod Dentofac Orthop. 2003;123(5):571-7.

23. Wilmes B, Nienkemper M, Drescher D. Application and effectiveness of a mini-implant- and tooth-borne rapid palatal expansion device: the hybrid hyrax. World J Orthod. 2010;11(4):323-30.

24. Wilmes $B$, Drescher D. A miniscrew system with interchangeable abutments. J Clin Orthod. 2008;42(10):574-80.

25. Cha B, Ngan PW. Skeletal anchorage for orthopedic correction of growing class III patients. Semin Orthod. 2011;17(2):124-37. doi:10.1053/ j.sodo.2010.12.005

26. Poletti L, Silvera AA, Ghislanzoni LT. Dentoalveolar class III treatment using retromolar miniscrew anchorage. Prog Orthod. 2013;14:7.

27. Kircelli BH, Pektas ZÖ. Midfacial protraction with skeletally anchored face mask therapy: a novel approach and preliminary results. American Journal of Orthodontics and Dentofacial Orthopedics. 2008;133(3):440-9. doi:10.1016/j.ajodo.2007.06.011.

28. Zhou YH, Ding P, Lin Y, Qui LX. Facemask therapy with miniplate implant anchorage in a patient with maxillary hypoplasia. Chin Med J. 2007;15:1372-5.

29. Cevidanes L, Baccetti T, Franchi L, McNamara Jr JA, De Clerck H. Comparison of two protocols for maxillary protraction: bone anchors versus face mask with rapid maxillary expansion. Angle Orthod. 2010;80(5):799-806.

30. De Clerck H, Cevidanes L, Baccetti T. Dentofacial effects of bone-anchored maxillary protraction: a controlled study of consecutively treated class III patients. American Journal of Orthodontics and Dentofacial Orthopedics. 2010;138(5):577-81. doi:10.1016/j.ajodo.2009.10.037

31. De Clerck HJ, Cornelis MA, Cevidanes LH, Heymann GC, Tulloch CJF. Orthopedic traction of the maxilla with miniplates: a new perspective for treatment of midface deficiency. Journal of Oral and Maxillofacial Surgery. 2009;67(10):2123-9. doi:10.1016/j.joms.2009.03.007.

32. Wilmes B, Nienkemper M, Ludwig B, Kau CH, Drescher D. Early class III treatment with a hybrid hyrax-mentoplate combination. J Clin Orthod. 2011;45(1):15-21.

33. Ludwig B, Glas B, Bowman SJ, Drescher D, Wilmes B. Miniscrew-supported class III treatment with the hybrid RPE advancer. J Clin Orthod. 2010;44(9):533-9.

34. Şar Ç, Arman-Özçırpı ı A, Uçkan S, Yazıcı AC. Comparative evaluation of maxillary protraction with or without skeletal anchorage. Am J Orthod Dentofac Orthop. 2011:139(5):636-49.
35. Bjork A. The face in profile: an anthoropological $x$-ray investigation of Swedish children and conscripts. Lund: Berlingska Boktrycheriet 1947;40-58.

36. Pancherz $\mathrm{H}$. The mechanism of class II correction in Herbst appliance treatment. A cephalometric investigation. Am J Orthod Dentofacial Orthop. 1982;82:104-13.

37. Haas AJ. Palatal expansion: just the beginning of dentofacial orthopedics. Am J Orthod. 1970;57:219-55

38. Nanda R. Biomechanical and clinical considerations of a modified protraction headgear. Am J Orthod Dentofac Orthop. 1980;78:125-39.

39. Ishii H, Morita S, Takeuchi Y, Shinji N. Treatment effects of combined maxillary and chincap appliance in severe skeletal class III cases. Am J Orthod Dentofac Orthop. 1987;92:304-12.

40. Merwin D, Ngan P, Hagg U, Yiu C, Wei SHY. Timing for effective application of anteriorly directed orthopedic force to the maxilla. Am J Orthod Dentofac Orthop. 1997;112:292-9.

\section{Submit your manuscript to a SpringerOpen ${ }^{\circ}$ journal and benefit from:}

- Convenient online submission

- Rigorous peer review

- Immediate publication on acceptance

- Open access: articles freely available online

- High visibility within the field

- Retaining the copyright to your article

Submit your next manuscript at $>$ springeropen.com 